\title{
The Two-Echelon Dual-Channel Models for the Intermodal Container Terminals of the China Railway Express Considering Container Accumulation Modes
}

\author{
Shujuan Guo ${ }^{1} \oplus$, Cuijie Diao ${ }^{1}$, Gang $\mathrm{Li}^{1,2, *}$ and Katsuhiko Takahashi ${ }^{3}$ \\ 1 College of Transportation Engineering, Dalian Maritime University, Dalian 116026, China; \\ guoshujuan@dlmu.edu.cn (S.G.); dcj0601@dlmu.edu.cn (C.D.) \\ 2 School of Traffic and Transportation Engineering, Dalian Jiaotong University, Dalian 116028, China \\ 3 Graduate School of Advanced Science and Engineering, Hiroshima University, \\ Higashi Hiroshima 7398527, Japan; takahasi@hiroshima-u.ac.jp \\ * Correspondence: ligangpe2012@hotmail.com
}

Citation: Guo, S.; Diao, C.; Li, G.; Takahashi, K. The Two-Echelon Dual-Channel Models for the Intermodal Container Terminals of the China Railway Express Considering Container Accumulation Modes. Sustainability 2021, 13, 2806. https://doi.org/10.3390/su13052806

Academic Editor: Marco Guerrieri

Received: 31 December 2020

Accepted: 1 March 2021

Published: 5 March 2021

Publisher's Note: MDPI stays neutral with regard to jurisdictional claims in published maps and institutional affiliations.

Copyright: (c) 2021 by the authors. Licensee MDPI, Basel, Switzerland. This article is an open access article distributed under the terms and conditions of the Creative Commons Attribution (CC BY) license (https:// creativecommons.org/licenses/by/ $4.0 /)$.

\begin{abstract}
China Railway Express (CR Express) is a pioneer of the Silk Road Economic Belt and the 21st Century Maritime Silk Road. The intermodal container terminal system consisting of a maritime terminal and a railway terminal is investigated in this paper. It connects the shipping route and the CR Express route. Typically, there are two container accumulation modes in the railway terminal to dispatch a train, i.e., the fixed-length and the fixed-time container accumulation modes. The intermodal container terminal system can be formulated as the two-echelon dual-channel supply chain model. The steady-state probability matrix is obtained by solving the equilibrium equations. The cooperation between the maritime terminal and the railway terminal is considered to accelerate the accumulation of the containers. The total revenue of the two terminals is used as the key system performance indicator. Numerical experiments are conducted to compare the fixed-length and the fixed-time container accommodation modes. The situations with and without cooperation between two terminals are also compared in the two container accumulation modes, respectively.
\end{abstract}

Keywords: intermodal container terminal; markov analysis; belt and road; container accumulation mode

\section{Introduction}

In 2013, China put forward the strategic concept of building "the Silk Road Economic Belt and the 21st Century Maritime Silk Road (B\&R)". As a pioneer of B\&R, China Railway Express (CR Express) is the train operating between China and Europe, which is a new type of intercontinental trade transport mode. Being faster than maritime transportation and cheaper than air transportation, the cargo volume of CR Express increases exponentially. The data from China State Railway Group Co., Ltd. shows that there were 8225 train journeys in 2019 (http: / / www.china-railway.com.cn; accessed on 3 January 2020). It was more than 843 times the cargo volume in 2011, which is the first year that CR Express operated. It included more than 65 CR Express routes connecting 56 Chinese cities with 49 European cities. At present, the Sino-Europe railway liners are mainly organized by the local governments in China independently. To achieve the economies of scale and increase the network coverage, CR Express has been suggested to create the cargo consolidation hubs. Many Chinese cities are competing to become the consolidation hubs of CR Express [1]. Currently, consigners are willing to choose rail-sea intermodal transportation. For example, Korea is seeking the benefits from CR Express. Wang and Yeo [2] have analyzed three seaports and two inland cities in China for the provision of transshipment services between Europe and South Korea.

This study focuses on an intermodal container terminal system comprising a maritime container terminal and a railway container terminal for offering multi-mode container 
transportation services. In order to satisfy the intermodal transportation demand of CR Express, both the maritime terminal and the railway terminal reserve a certain amount of storage yards for the CR Express. The process of transporting containers from the intermodal container terminals to the consolidation hubs of CR Express is as follows. Firstly, the containers are unloaded from the vessel using quayside cranes to the maritime container terminal. Next, the containers are stocked in the reserved storage yard of the maritime terminal, waiting to be transported to the inland consolidation hubs of CR Express by truck or train. The containers transported by truck are directly picked up from the maritime terminal to be transported to the consolidation hubs of CR Express. Those transported by train are picked up from the maritime terminal and delivered to the railway terminal for waiting to be loaded on a train and sent to the consolidation hubs of CR Express. Eventually, the containers in the consolidation hubs of CR Express are distributed to the destinations of Europe or Central Asia by CR Express. In this study, by regarding the maritime terminal and the railway terminal as the two-echelon inventories, and the truck and railway modes as the dual-channel, the intermodal container terminal system is formulated as the two-echelon dual-channel supply chain model [3].

Typically, there are two container accumulation modes in the railway terminal to dispatch a train. The fixed-length container accumulation mode is that the train simply departs when the number of containers accumulated in the railway terminal is sufficient to meet the full capacity of the train [4]. Different from the fixed-length mode, the trains operate with schedules in the fixed-time container accumulation mode. The train can depart only if the system is in working state and the transportation demand meets the minimum requirement. In the fixed-time container accumulation mode, although the number of containers can be less than the full capacity of the train, it should be a sufficient number. Otherwise, the train may be canceled. This is because of the economic scale and the effectiveness of the transportation [5].

Recently, maritime terminals intend to cooperate with the railway terminals. For example, the Implementation Plan of Transport Structure Adjustment has been issued by Shanghai. It aims to develop an intermodal freight transportation system for information sharing between maritime terminal and railway terminals [6]. The intelligent Transportation Systems are developed to provide the possibilities of the cooperative planning among multiple participants in the intermodal transportation through the rapid exchange of the information [7]. In this study, the information of the number of containers accumulating in the railway terminal is shared between the railway terminal and the maritime terminal. Their cooperation helps to accelerate the accumulation of containers in the railway terminal. It decreases the waiting time in the railway terminal dramatically and promotes the shift from truck to train. The train is a more environment-friendly mode and produces less gas pollution. It can also improve the satisfaction level of consigners.

The remainder of this study is organized as follows. In Section 2, the literature is reviewed. The models for two-echelon dual-channel models of two container accumulation modes are presented in Section 3. In addition, the steady-state probability matrix is obtained by solving the equilibrium equations, and the performance indicators are presented in Section 3. Numerical experiments and conclusions are given in Sections 4 and 5, respectively.

\section{Literature Review}

CR Express is one of the most remarkable achievements of the Silk Road Economic Belt. An increasing number of works have focused on the CR Express. A binary Logit model was employed to analyze the hinterland patterns of the 5 typical CR Express routes [8]. Shao et al. [9] proposed a large-scale transnational high-speed railway construction evaluation problem. The construction priority of the road sections for the high-speed railway was determined. Sun et al. [10] investigated the selection of consolidation centers of CR Express in China and constructed the consolidation networks based on the shortest highway distance within $500 \mathrm{~km}$ from origin cities to the consolidation centers. Zhao et al. [1] 
firstly evaluated the significance of city nodes by complex network theory. Then, a mixed integer programming method was proposed to find consolidation hubs in China for the CR Express. Wang et al. [11] found that the B\&R had a positive impact on strengthening the connectivity of the transportation network and promoting the intermodal transportation.

"Silk Road Economic Belt" and "21st century Maritime Silk Road" are two equally important parts in the B\&R initiative [12-14]. Considering the competition between CR Express and the shipping route, a bi-level programming model was proposed for the Chinese liner shipping companies to re-construct their liner shipping service networks [15]. There are also some studies researching on the cooperation between CR Express and maritime routes. Kuzmicz and Pesch [16] analyzed the models and a variety of solutions of the empty container repositioning problems in the context of the Eurasian intermodal transportation. Xie et al. [17] studied that rail and shipping liner firms cooperate together to share the empty container resources between them. Firstly, the optimal empty container repositioning and replenishment policies were proposed for the centralized system. Then, a bilateral buy-back contract was designed to coordinate the decentralized system. Wang and Yeo [2] used Fuzzy Delphi and Fuzzy methods to find the best intermodal routes for transporting cargo from Korea to Central Asia by CR Express. Wei and Dong [18] focused on the new cross-border logistics network, which connects the maritime logistics network with the inland cross-border logistics network through dry ports. The organizational optimization problem of inland import and export goods were studied. However, the intermodal terminals which serve as hubs to transfer the containers between the maritime and CR Express routes are not well researched.

There are many studies focusing on the container terminal operations and management. Some researchers are further improving transportation services through a variety of means, including service integration, infrastructure investment, and information systems implementation [19]. Carlo et al. [20] presented an in-depth overview of storage yard operations of the maritime container terminal. A classification scheme for storage yard operations was proposed. Guo et al. [21] proposed a yard crane dispatching algorithm based on real-time data-driven simulation to solve the problem of yard crane job sequencing to minimize average vehicle waiting time. The application of Radio Frequency Identification (RFID) and other technologies in container logistics operations in ports was evaluated to realize real-time tracking of containers and equipment in the maritime terminal [22,23]. In terms of railway terminal, Boysen et al. [24] presented an exhaustive review of railway terminal operational problems and challenges. Cordeau et al. [4] reviewed papers regarding the scheduling problem in the freight transport of train. The fixed-length and fixed-time accumulation modes were discussed. In Reference [5], a finite-capacity queueing system was proposed to optimize the size of the container yard of the railway station and the frequency of the shift for CR Express. A fixed-time accumulation mode was studied in the railway terminal of CR Express. Few studies investigated the railway terminals and maritime terminal in an integrated manner. Hu et al. [25] studied the inter-terminal transport moving containers between the maritime terminal and the railway terminal. A mathematical model integrating inter-terminal transport and rail yard operation was proposed and solved by a tabu search algorithm. Caballini et al. [26] presented a planning approach to optimize railway operations in seaport terminals by adopting a queue-based discrete-time model. However, the comparison of the container accumulation modes and the cooperation between maritime and railway terminals are not well studied in these papers.

In this study, the two container accumulation modes under the cooperation between the maritime terminal and the railway terminal are investigated. The contributions of this study to the literatures are as follows:

- This study formulates the operation at intermodal container terminals for CR Express based on a two-echelon dual-channel supply chain model.

- $\quad$ The fixed-length and the fixed-time container accumulation modes are investigated and compared. 
- The cooperation between a maritime terminal and a railway terminal is considered. Specifically, the accelerated accumulation scenario is proposed.

\section{Two-Echelon Dual-Channel Models of Two Container Accumulation Modes}

In this section, the two-echelon dual-channel models of the intermodal terminals considering two container accumulation modes are presented. The assumptions and the parameters are presented as follows:

1. The intermodal container terminal system receives stochastic demand of transportation containers from the maritime terminal to the CR Express consolidation hub. Some consigners prefer to transport by railway and others prefer to transport by truck.

2. Each transportation demand has an independent arrival rate.

3. The transportation demand by truck arrives at the maritime container terminal in accordance with a Poisson process at constant rate $\lambda_{d}$. When transportation demand by truck arrives, one container is loaded on the truck and leaves the system.

4. The transportation demand by train arrives at the railway container terminal in accordance with a Poisson process at constant rate $\lambda_{r}$. When the transportation demand by train arrives, the container transported is transferred from the maritime terminal to the railway terminal.

5. The total transportation demand rate is $\lambda=\lambda_{d}+\lambda_{r}$. The preference rate of the transportation demand by railway is $\alpha$. Hence, we have $\lambda_{r}=\alpha \lambda, \lambda_{d}=(1-\alpha) \lambda$. The inter-arrival time between the successive demands follows an exponential distribution with mean $1 / \lambda$.

6. The containers at the maritime terminal are dispatched from the ship in accordance with a Poisson process at constant rates $\mu_{w}$. The processing time for the maritime terminal follows an exponential distribution with mean $1 / \mu_{w}$.

7. The intermodal terminals system has two-echelon inventories, the maritime terminal and the railway terminal.

8. When the number of containers in the railway terminal satisfies the requirement to dispatch a train, the containers are loaded to the train. The loading time of containers on to a train follows an exponential distribution with mean $1 / \mu_{l}$. After loading the containers on the train, the train leaves the system.

9. The maximum of containers in the storage yards reserved for CR Express in the maritime terminal and the railway terminal are $x_{l}$ and $y_{l}$.

10. It is assumed that in the situation with cooperation, the maritime and railway terminals share the information that the trains are ready to depart. It is allowed that the containers previously transported by truck can be shifted to be transported by train.

11. In the fixed-time container accumulation mode, the train can depart only in the working state.

\subsection{The Two-Echelon Dual-Channel Model of the Fixed-Time Container Accumulation Mode}

The two-echelon dual-channel model with fixed-time is shown in Figure 1. The container accumulation mode of fixed-time is a two-state Markov Chain. It can be characterized as a Markov-modulated Poisson process of two-state (MMPP (2)).

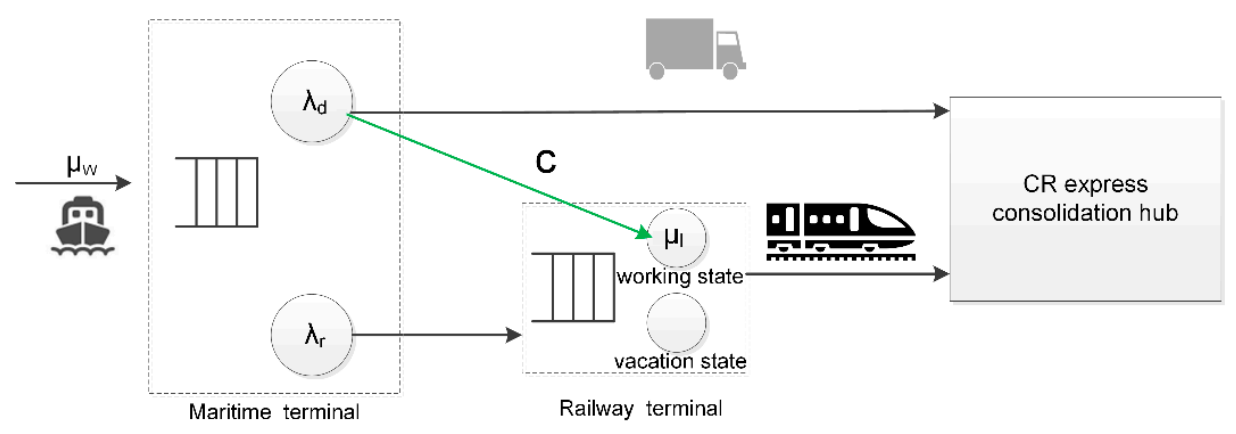

Figure 1. The two-echelon dual-channel model of the fixed-time container accumulation mode. 
The states' transition diagram of the fixed-time container accumulation mode with MMPP (2) is shown in Figure 2. An MMPP (2) switches between the working state and the vacation state. Let $p$ denote the state of $\operatorname{MMPP}(2), p \in\{0,1\}$, where $p=1$ presents the working state of the railway terminal, whereas $p=0$ represents the vacation state. Figure $2 \mathrm{a}$ presents the vacation state of the railway terminal, and Figure $2 b$ represents the working state. Circles indicate states of the system with different values of the $(k, y, p)$, where $k$ is the sum of containers in the maritime terminal and railway terminal and $k=x+y$. $x$ is the number of containers at the maritime terminal, and $y$ is the number of containers at the railway terminal. Arrows indicate system transition rates. The explanations of the transition rates in Figure 2 are as follows: If one container at the maritime terminal is transported to the consolidation hub of CR Express by truck at rate $\lambda_{d}$, the inventory at the maritime terminal decreases one unit and the state $(k, y, p)$ changes to the state $(k-1, y, p)$. If one container from the ship is unloaded to the maritime terminal at rate $\mu_{w}$, the inventory at the maritime terminal increases one unit and the state $(k, y, p)$ changes to the state $(k+1, y, p)$. When one container is transported from the maritime terminal to the railway terminal at rate $\lambda_{r}$, the inventory at the maritime terminal decreases one unit and the inventory at the railway terminal increases one unit and the state $(k, y, p)$ changes to the state $(k, y+1, p)$.

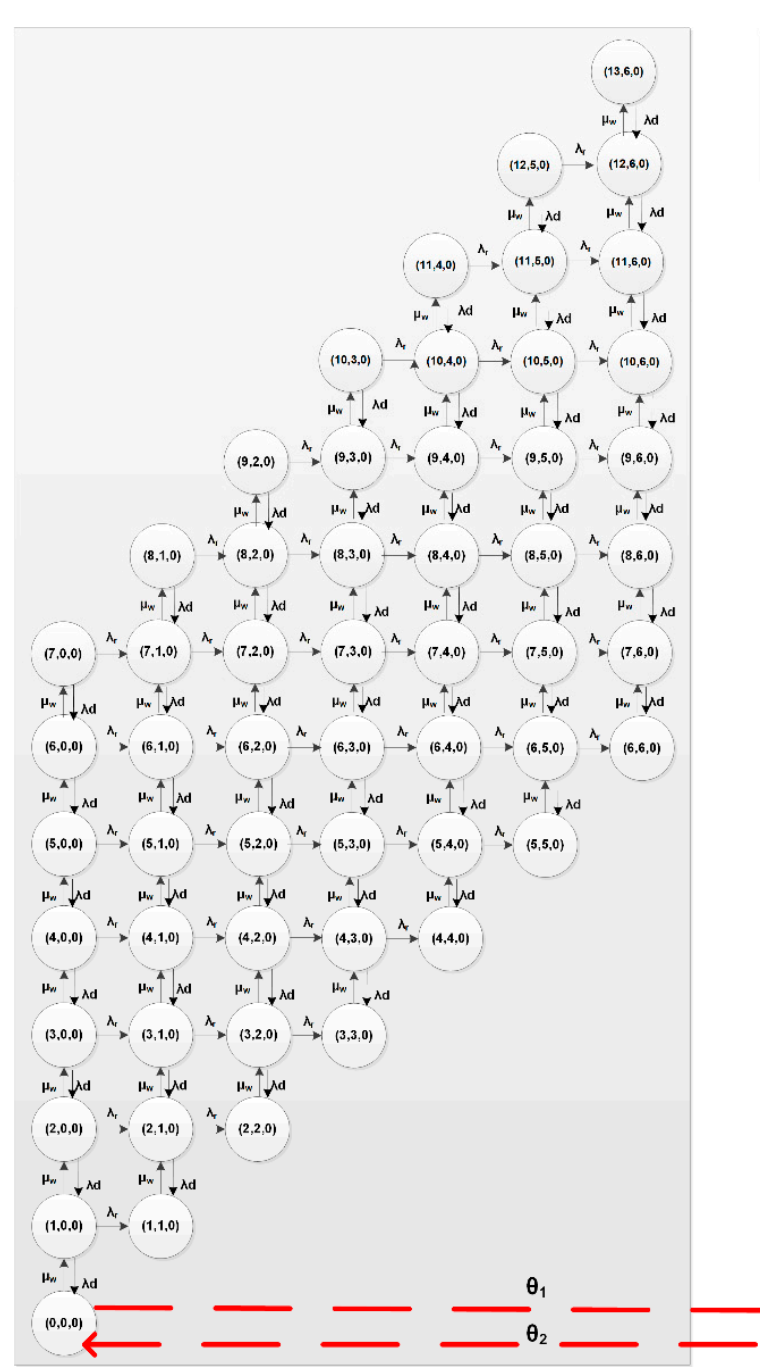

(a) vacation state

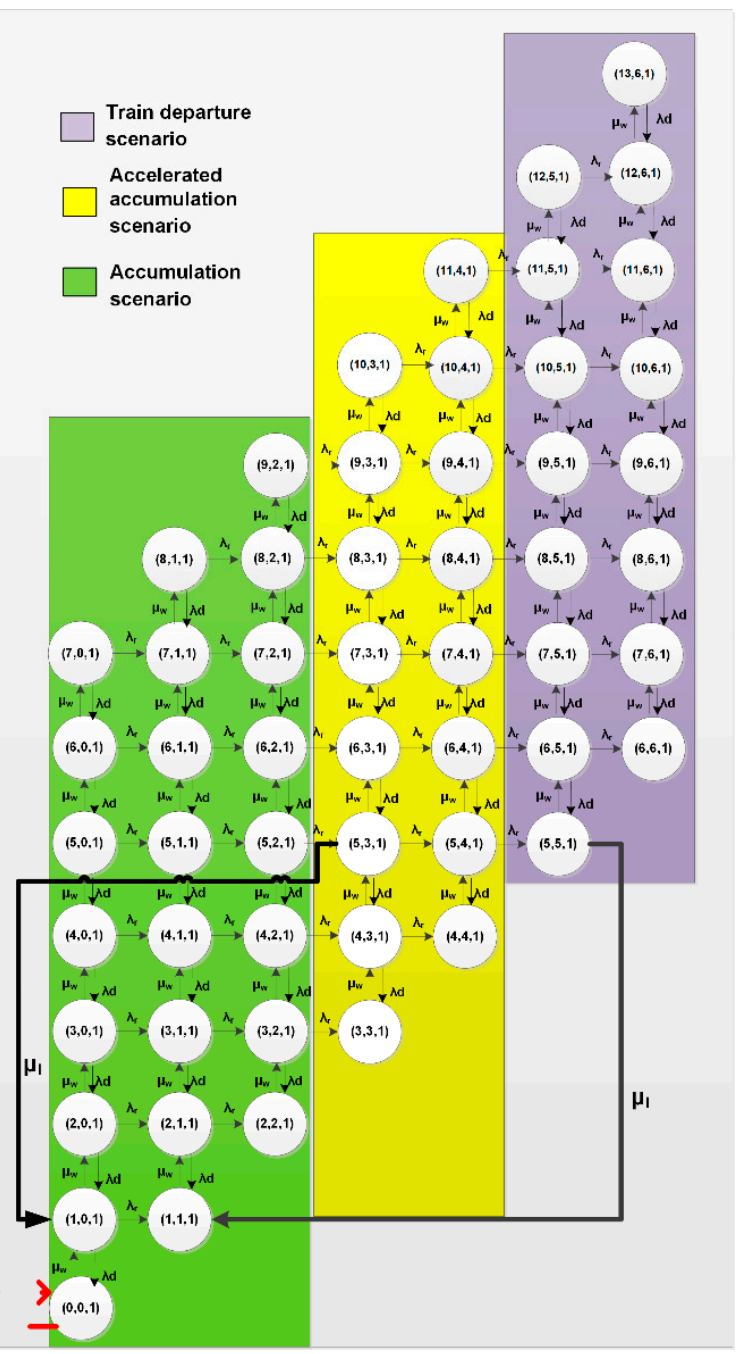

(b) working state

Figure 2. The states transition diagram of the fixed-time container accumulation mode $\left(x_{l}=7, y_{l}=6, b=4\right.$, and $\left.a=3\right)$. (a) vacation state; (b) working state. 
In the vacation state, the containers are accumulated continually in the railway terminal. In the working state, the number of containers in the railway terminal is checked whether to satisfy the requirement of dispatching a train. If the requirement is satisfied, the containers are loaded on the train and the train departs. Otherwise, the container will wait in the terminal for the next time interval of working state. This strategy will increase the utilization of the train. Let $\theta_{1}$ and $\theta_{2}$ denote the transition rates between the two states of the MMPP (2). For example, Saturday and Sunday are the vacation days, and the railway terminal dispatches trains on working days from Monday to Friday. Then, $\theta_{1}^{-1}=2$ days and $\theta_{2}{ }^{-1}=5$ days. It should be noted that these transitions occur from the state $(k, y, 0)$ to the state $(k, y, 1)$ with rate $\theta_{1}$ and from the state $(k, y, 1)$ to the state $(k, y, 0)$ with rate $\theta_{2}$. For ease of exposition, some arrows with rate $\theta_{1}$ and $\theta_{2}$ between states $(k, y, 1)$ and $(k, y, 0)$ are not shown.

In the working state of the fixed-time container accumulation mode, there are three scenarios of considering the accumulation states of the train, which are accumulation, accelerated accumulation, and train departure scenarios. Let $b$ be the full capacity of a train. Let $a$ present a threshold in the working state. When the number of containers waiting to be transported by a train in the railway terminal is no less than $a$, the system changes from the accumulation scenario into the accelerated accumulation scenario. The three scenarios in the working state and the transition rates specified in each scenario are described as follows:

- Accumulation scenario: If $y<a$, there is not enough containers in the railway terminal, and the containers are continuously accumulated.

- Accelerated accumulation scenario: If $a \leq y<b$, the number of containers reaches the minimum requirements of dispatching a train. This information is shared to the maritime terminal. The containers in the maritime terminal could be shifted to the railway terminal and be directly loaded on the train, avoiding waiting in the railway terminal. Let $c$ be the quantity of shifting containers, then $c=\min \{k-y, b-y\}$. The state $(k, y, 1)$ changes to the state $(k-y-c, 0,1)$ at the loading rate of $u_{l}$ and then a train departs. For example, the state $(5,3,1)$ changes into state $(1,0,1)$ at the loading rate of $u_{l}$ in Figure $2 \mathrm{~b}$.

- Train departure scenario: If $y \geq b$, the train will depart with the full capacity and the state $(k, y, 1)$ changes to state $(k-b, y-b, 1)$. For example, the state $(5,5,1)$ switches into state $(1,1,1)$ at the loading rate of $u_{l}$ in Figure $2 \mathrm{~b}$.

The system states are presented by the generator $Q^{1}$. To represent in a compact form, the states are arranged in an increasing lexicographical order. The generator matrix $Q^{1}$ is obtained as follows:

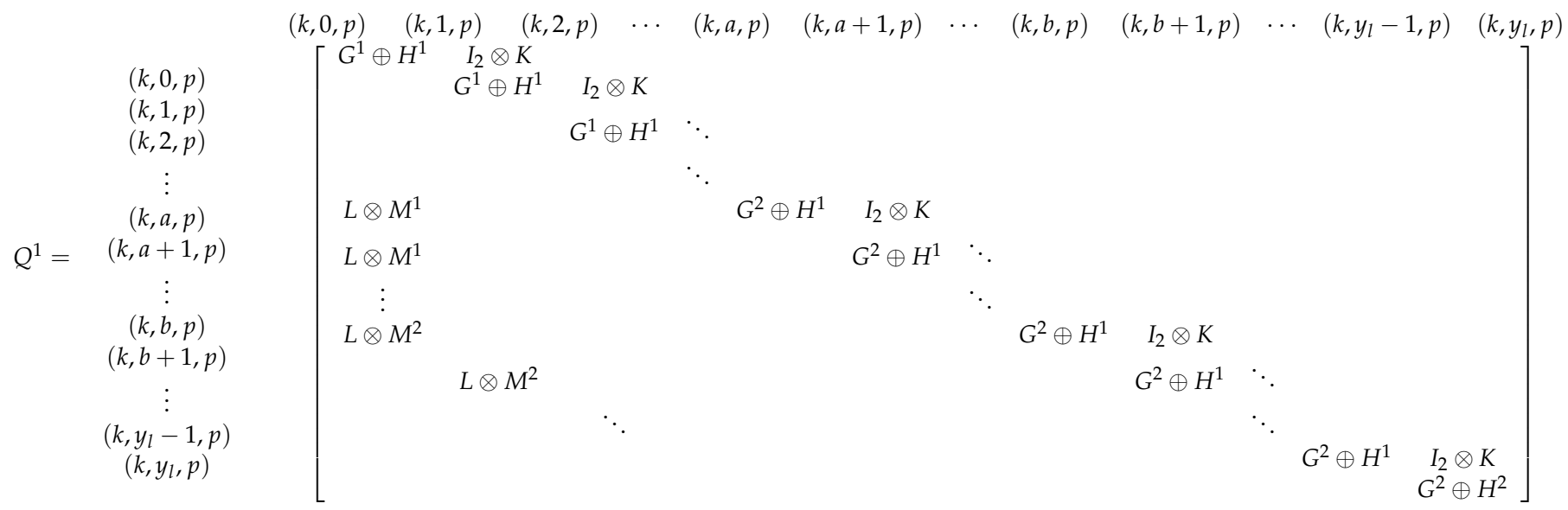

where $I_{2}$ is the identity martix of order 2 , the operators $\oplus$ represent the Kronecker sum and $\otimes$ represent the Kronecker product respectively, and for $p \in\{0,1\}$. Matrices $G^{1}, G^{2}, L, H^{1}$, $H^{2}, K, M^{1}$, and $M^{2}$ are defined in Appendix A. 


\subsection{The Two-Echelon Dual-Channel Model of the Fixed-Length Container Accumulation Mode}

The fixed-length container accumulation mode is that the train only departs when the number of containers in the railway terminal reach the full capacity of the train. Otherwise, the train waits in the railway terminal until enough containers are accumulated. The twoechelon dual-channel model of the fixed-length container accumulation mode is shown in Figure 3.

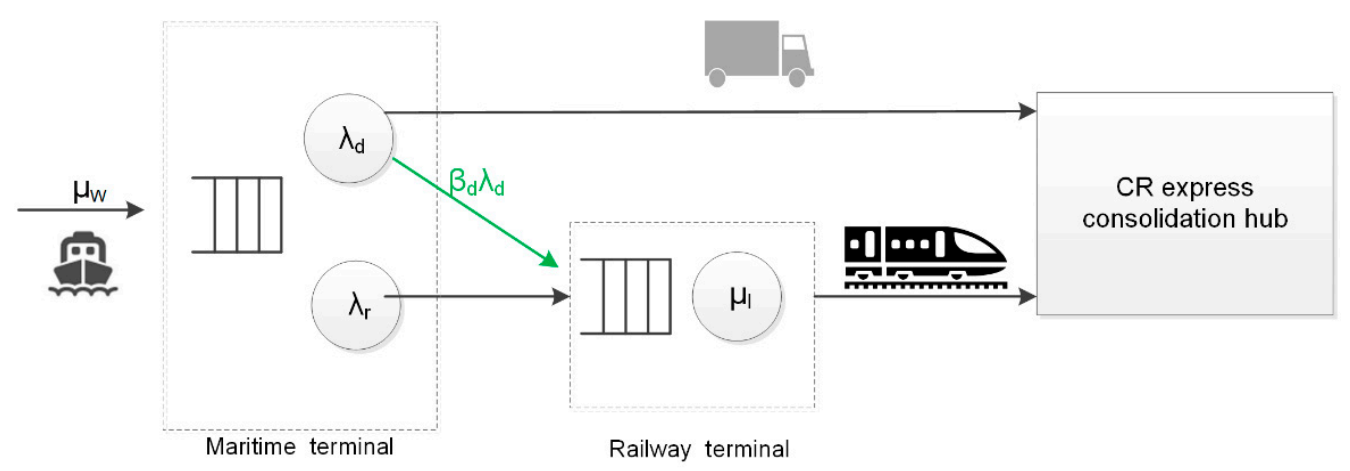

Figure 3. The two-echelon dual-channel model of the fixed-length container accumulation mode.

There are also three scenarios of considering the accumulation states of the train. When $y<b / 2$, it is the accumulation scenario, and the containers are continually accumulated in the railway terminal. When $b / 2 \leq y<b$, it is the accelerated accumulation scenario. It means that the containers in the railway terminal almost reach the full capacity of the train and the train is going to depart. This information is shared with the maritime terminal. The consigners notice that the train will be dispatched soon and the waiting time in the railway terminal will be decreased dramatically. Some proportion of the containers previously planning to transport by truck shift to transport by train. When $y \geq b$, there are enough containers at the railway terminal to dispatch a train and it is the train departure scenario. The containers are loaded to a train and then disappear in the system with the train departure.

As the space is limited, and the analytical process of the fixed-length container accumulation mode is similar to the fixed-time container accumulation mode, the analysis of the fixed-length container accumulation mode is excluded in this paper. For the state transition diagram, the explanations of transition rates, three scenarios, and the generator matrix $Q^{2}$, readers are recommended to refer to our previous conference paper [27].

\subsection{Solving the Equilibrium Equations}

The steady-state probability matrix $\pi$ of all states in the system is obtained by using the standard solution method given by Grassmann and Stanford [28]. In terms of the fixed-length container accumulation mode, the steady-state probability matrix $\pi$ is defined as $\pi=\left[\vec{\pi}_{0}, \vec{\pi}_{1}, \ldots, \vec{\pi}_{n}, \ldots, \vec{\pi}_{y_{l}}\right]$, where $\vec{\pi}_{n}=\left[\pi_{(0, n)}, \pi_{(1, n)}, \pi_{(2, n)}, \ldots, \pi_{\left(x_{l}-1, n\right)}, \pi_{\left(x_{l}, n\right)}\right]$, $\forall n \geq 0$. Whereas the steady-state probability matrix for the fixed-time container accumulation mode is defined as $\pi=\left[\vec{\pi}_{0}, \vec{\pi}_{1}, \ldots, \vec{\pi}_{n}, \ldots, \vec{\pi}_{y_{l}}\right]$, where $\vec{\pi}_{n}=\left[\pi_{(0, n, 0)}, \pi_{(1, n, 0)}, \ldots\right.$, $\left.\pi_{\left(x_{l}+n, n, 0\right)}, \pi_{(0, n, 1)}, \pi_{(1, n, 1)}, \cdots, \pi_{\left(x_{l}+n, n, 1\right)}\right], \forall n \geq 0$. The first $x_{l}+1$ elements in vector $\vec{\pi}_{n}$ represent the steady-state probabilities corresponding to the vacation state, and the remaining elements correspond to the working state of the fixed-time modes. Since $Q^{f}$ presents the generator matrix, the steady-state probability matrix $\pi$ is obtained by solving the equilibrium equations $\pi \cdot Q^{f}=0$, and the equilibrium equations are subject to the constraint that the sum of the all elements of the steady-state probability matrix $\pi$ is equal to 1. 


\subsection{Performance Indicators}

The key system performance indicator used in this study is the total revenue of the maritime terminal and the railway terminal. It consists of the operation revenue of the maritime terminal, the operation revenue of the railway terminal, the shifting revenue, and the train departure revenue. The operation revenue is generated from the use of the resources of the terminal. It mainly includes the revenue of loading and unloading operations, storage operations, and short-haul transportation operations within the system. The shifting revenue is the revenue generated when the containers that were previously planned to transport by truck shift to transport by train in the acceleration accumulation scenario. The train departure revenue is proportional to the number of trains that depart from the railway terminal.

The following equations are calculated with the steady-state probability $\pi$. Let $i$ present the terminals. $i=1$ represents the maritime terminal and $i=2$ means the railway terminal. Let $j$ represent the container accumulation modes. $j=1$ means the fixed-length container accumulation mode and $j=2$ means the fixed-time container accumulation mode.

Let $t s q_{i}^{j}$ be the container storage quantity at terminal $i$ in the container accumulation mode $j . t s q_{i}^{j}$ is calculated by Equation (1):

$$
t s q_{1}^{1}=\sum_{x=0}^{x_{l}} \sum_{y=0}^{y_{l}} x \pi_{x y}, t s q_{2}^{1}=\sum_{x=0}^{x_{l}} \sum_{y=0}^{y_{l}} y \pi_{x y}, t s q_{1}^{2}=\sum_{p=0}^{1} \sum_{k=0}^{x_{l}+y_{l}} \sum_{y=0}^{y_{l}}(k-y) \pi_{k y p}, t s q_{2}^{2}=\sum_{p=0}^{1} \sum_{k=0}^{x_{l}+y_{l}} \sum_{y=0}^{y_{l}} y \pi_{k y p}
$$

Let $C S T_{i}$ be the unit container operation revenue at terminal $i . R s r_{i}^{j}$ is the operation revenue of the terminal $i$ in the container accumulation mode $j$, which is calculated by Equation (2):

$$
R s r_{i}^{j}=C S T_{i} \times t s q_{i}^{j}
$$

Let $t t q^{j}$ be the container shifting quantity from the truck to the railway in the accelerated accumulation scenario of the container accumulation mode $j . t t q^{j}$ is obtained by Equations (3) and (4):

$$
\begin{gathered}
t t q^{1}=\sum_{x=0}^{x_{l}} \sum_{y=b / 2}^{b} \beta_{d} \lambda_{d} \times \pi_{x y} \\
t t q^{2}=\sum_{k=0}^{x_{l}+y_{l}} \sum_{y=a}^{b} c \times \mu_{l} \pi_{k y 1}, \text { where } c=\min \{k-y, b-y\}
\end{gathered}
$$

Let CSP be the unit container shifting revenue. The shifting revenue $R_{s h f}^{j}$ is calculated using

$$
R_{s h f}^{j}=C S P \times t t q^{j}
$$

vnum $^{j}$ is the number of trains dispatched in the container accumulation mode $j$, which is calculated by Equation (6):

$$
\text { vnum }^{1}=\sum_{x=0}^{x_{l}} \sum_{y=b}^{y_{l}} \mu_{l} \pi_{x y}, \text { vnum }^{2}=\sum_{k=0}^{x_{l}+y_{l}} \sum_{y=a}^{y_{l}} \mu_{l} \pi_{k y 1}
$$

Let $C P R$ be the unit train departure revenue, and the train departure revenue $R_{d e p}^{j}$ is calculated using Equation (7):

$$
R_{\text {dep }}^{j}=C P R \times \text { vnum }^{j}
$$


Finally, the total revenues $T R^{j}$ in the container accumulation modes $j$ are calculated using Equation (8), as follows:

$$
T R^{j}=R s r_{1}^{j}+R s r_{2}^{j}+R_{s h f}^{j}+R_{d e p}^{j}
$$

\section{Numerical Experiments}

In this section, we will seek the answers to the following three questions with the aid of numerical experiments:

Q1. How is the performance of the two container accumulation modes in terms of the total revenue (Section 4.2)?

Q2. Should the maritime terminal and the railway terminal cooperate with each other (Section 4.3)?

Q3. How does the important parameter $\alpha$ affect the total revenue (Section 4.4)?

\subsection{Setup of Experiments}

The full capacity of the train is $b=40$, and the threshold in the working state of the fixed-time container accumulation mode is $a=20$. The preference rate of the railway transportation mode $\alpha$ and the shifting rate from truck to railway $\beta_{d}$ are set as 0.6 and 0.5 , respectively. The loading time of containers on the train follows an exponential distribution with $\mu_{l}=5$. The capacities of the storage yards reserved for the CR Express in the maritime terminal and the railway terminal are $x_{l}=y_{l}=60$. The arrival rate $\mu_{w}$ and total demand rate $\lambda$ are set to $(10,9),(15,13),(25,20),(40,30),(60,45)$, and $(80,60)$ in this subsection, to present the small and large intermodal transportation demand. $\left(\theta_{1}, \theta_{2}\right)$ is set to $(0.5,0.1)$, $(0.5,0.2),(0.5,0.5),(0.2,0.2),(0.2,0.5)$, and $(0.1,0.5)$ to present different types of fixed-time container accumulation modes.

The revenue parameters considered in this study are set as follows. The unit container operation revenue at maritime and railway terminals are $C S T_{1}=5$ and $C S T_{2}=5$, respectively. The unit container shifting revenue is $C S P=15$. The unit train departure revenue is $C P R=150$.

\subsection{Comparing Results of Two Container Accumulation Modes}

In this subsection, the two container accumulation modes are compared. Figure 4 shows the total revenues of the container accumulation modes under the different intermodal transportation demands.

First, the different types of the fixed-time container accumulation modes are compared. As shown in Figure 4, the total revenues of all of the container accumulation modes increase, as the intermodal transportation demand increases. In addition, the increment degree of the total revenue decreases with the decrease of the ratio of $\theta_{1}$ to $\theta_{2}$. Generally, the fixed-time container accumulation mode with the minimum ratio of $\theta_{1}$ to $\theta_{2}$ (i.e., $\left.(0.1,0.5)\right)$ performs best in the smallest demand of $(10,9)$. Whereas the fixed-time container accumulation mode with the maximum ratio of $\theta_{1}$ to $\theta_{2}$ (i.e., $\left.(0.5,0.1)\right)$ is superior to others in the largest demand of $(80,60)$. The reasons are as follows: In the vacation days, the containers are accumulated in the railway terminal. During the working days, if the number of containers reach the minimum requirement for dispatching a train, the train could depart. When the demand is small, more vacation days are needed in order to accumulate enough containers. Therefore, the small ratios of $\theta_{1}$ to $\theta_{2}$ are preferred under the small intermodal transportation demand. It is vice versa under the large intermodal transportation demand. Furthermore, when the ratio of $\theta_{1}$ to $\theta_{2}$ is 1 , i.e., $\left(\theta_{1}=\theta_{2}\right)$, the comparison between different values of $\theta_{i}$ is conducted. Under the small intermodal transportation demand, the smaller value of $\theta_{i}$ $\left(\theta_{1}=\theta_{2}=0.2\right)$ performs better than the bigger value $\left(\theta_{1}=\theta_{2}=0.5\right)$. This is because the vacation time is long enough to collect the containers for the train. It is vice versa under the large intermodal transportation demand. 


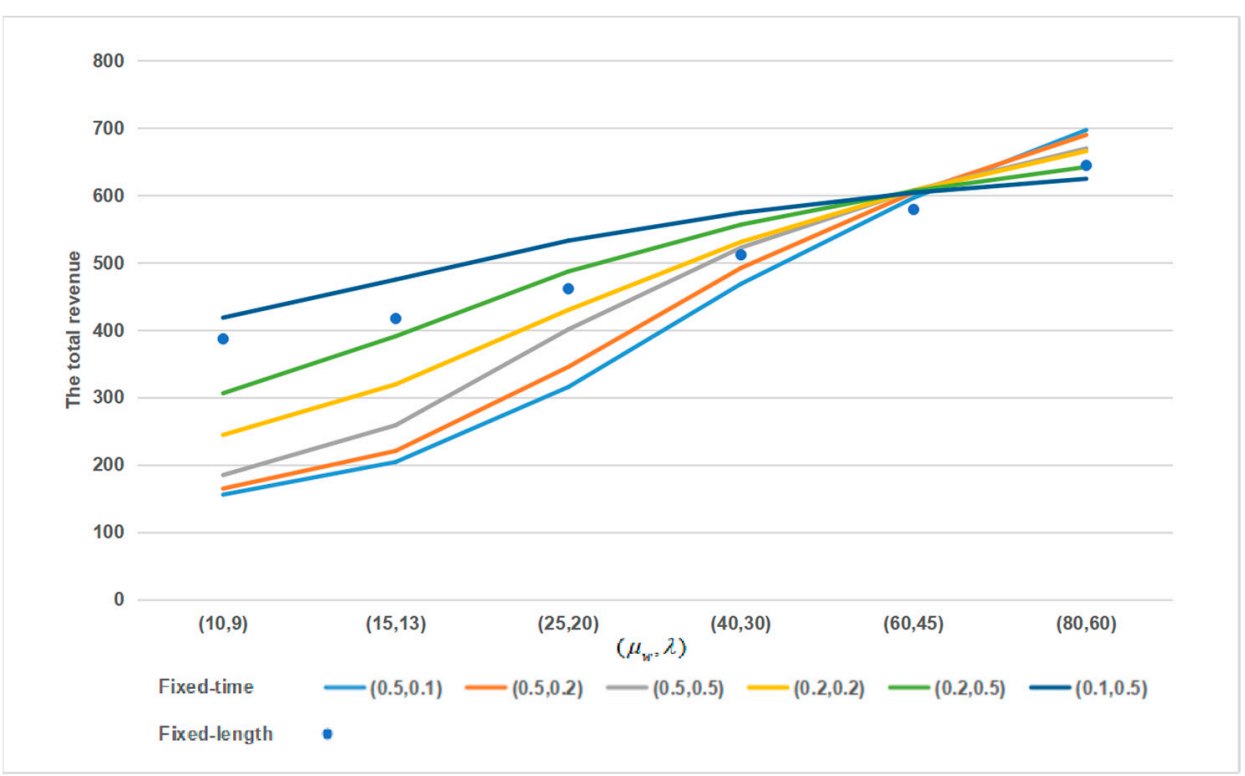

Figure 4. The total revenues of the container accumulation modes under different intermodal transportation demands.

Then, the fixed-length and fixed-time container accumulation modes are compared. Table 1 shows results of the total revenues of the different types of fixed-time container accumulation mode minus the total revenues of the fixed-length container accumulation mode. When the demand is $(60,45)$, all of the fixed-time container accumulation modes are better than the fixed-length container accumulation mode. Under the small intermodal transportation demand, the fixed-time container accumulation modes with small ratio of $\theta_{1}$ to $\theta_{2}$ are better than the fixed-length container accumulation mode, and the ones with large ratio of $\theta_{1}$ to $\theta_{2}$ are worse than the fixed-length container accumulation mode. It is vice versa under the large intermodal transportation demand. These are further explained in Section 4.3 by the composition of the total revenue of the container accumulation modes.

Table 1. The differences of the total revenues between the fixed-time and the fixed-length container accumulation modes.

\begin{tabular}{|c|c|c|c|c|c|c|}
\hline$\underbrace{}_{\left(\mu_{w}, \lambda\right)}\left(\theta_{1}, \theta_{2}\right)$ & $(0.5,0.1)$ & $(0.5,0.2)$ & $(0.5,0.5)$ & $(0.2,0.2)$ & $(0.2,0.5)$ & $(0.1,0.5)$ \\
\hline$(10,9)$ & -231.37 & -222.38 & -202.27 & -142.68 & -80.76 & 31.50 \\
\hline$(15,13)$ & -213.06 & -196.58 & -158.43 & -97.71 & -26.28 & 57.83 \\
\hline$(25,20)$ & -145.91 & -116.06 & -60.37 & -31.51 & 25.67 & 71.41 \\
\hline$(40,30)$ & -43.12 & -19.53 & 10.67 & 19.12 & 44.86 & 62.46 \\
\hline$(60,45)$ & 17.30 & 25.15 & 28.53 & 28.22 & 27.66 & 24.88 \\
\hline$(80,60)$ & 52.57 & 45.39 & 25.22 & 21.30 & -2.29 & -19.82 \\
\hline
\end{tabular}

\subsection{Results of with Cooperation and without Cooperation between Two Terminals}

In this subsection, the situations with and without cooperation between the maritime terminal and the railway terminal are compared. The $\left(\theta_{1}, \theta_{2}\right)$ is set at $(0.5,0.1)$ as an example of the fixed-time container accumulation mode. The experiment setup in the situation with cooperation is the same as mentioned in Section 4.1. In the situations without cooperation, $\beta_{d}$ is set to 0 in the fixed-length container accumulation mode, and $a=b=40$ in the fixedtime container accumulation mode, respectively. In this way, the accelerated accumulation scenario is removed.

The total revenues in the situations with cooperation and without cooperation are compared in Table 2. For both container accumulation modes, as the demands of the intermodal transportation increase, the total revenues in the situation with cooperation 
increase much faster than those in the situation without cooperation. For the fixed-length container accumulation mode, the total revenues in the situations with cooperation are better than the ones in the situations without cooperation for all demands. However, the differences are much less when the intermodal transportation demands are small. For the fixed-time container accumulation mode, when the intermodal transportation demands are small, the situations without cooperation are better than the situations with cooperation. It is vice versa when the intermodal transportation demands become larger. Therefore, the maritime terminal and the railway terminal need not cooperate when the intermodal transportation demand is small. However, the two terminals should cooperate when the intermodal transportation demand increases to some extent.

Table 2. The differences of the total revenues between with and without cooperation.

\begin{tabular}{ccccccc}
\hline & \multicolumn{3}{c}{ Fixed-Length } & \multicolumn{3}{c}{ Fixed-Time } \\
\cline { 2 - 7 }$\left(\boldsymbol{\mu}_{\boldsymbol{w}}, \boldsymbol{\lambda}\right)$ & $\begin{array}{c}\text { With } \\
\text { Cooperation }\end{array}$ & $\begin{array}{c}\text { Without } \\
\text { Cooperation }\end{array}$ & Difference & $\begin{array}{c}\text { With } \\
\text { Cooperation }\end{array}$ & $\begin{array}{c}\text { Without } \\
\text { Cooperation }\end{array}$ & Difference \\
\hline$(10,9)$ & 386.73 & 378.64 & 8.09 & 155.37 & 389.44 & -234.07 \\
$(15,13)$ & 416.96 & 402.10 & 14.86 & 203.91 & 415.77 & -211.86 \\
$(25,20)$ & 461.21 & 434.50 & 26.71 & 315.3 & 450.51 & -135.21 \\
$(40,30)$ & 511.57 & 467.97 & 43.6 & 468.45 & 484.45 & -16.00 \\
$(60,45)$ & 578.93 & 510.31 & 68.62 & 596.23 & 524.00 & 72.23 \\
$(80,60)$ & 644.35 & 551.60 & 92.75 & 696.92 & 560.32 & 136.60 \\
\hline
\end{tabular}

The reason can be explained by the compositions of the total revenues. The compositions of the total revenues of the fixed-length and the fixed-time container accumulation modes are shown in Figures 5 and 6, respectively. In each figure, there are two situations with and without cooperation between the terminals. The total revenue in the situations with cooperation consists of four parts, as explained in Section 3.4. However, the total revenue in the situations without cooperation consists of three parts, excluding the shifting revenue.

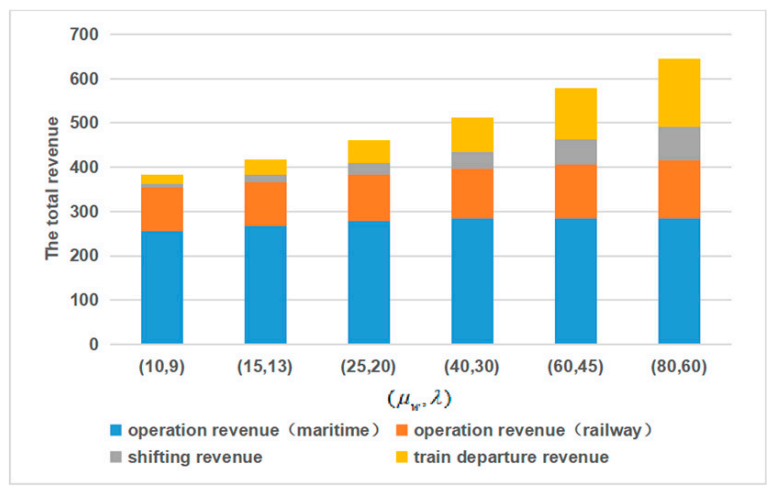

(a)

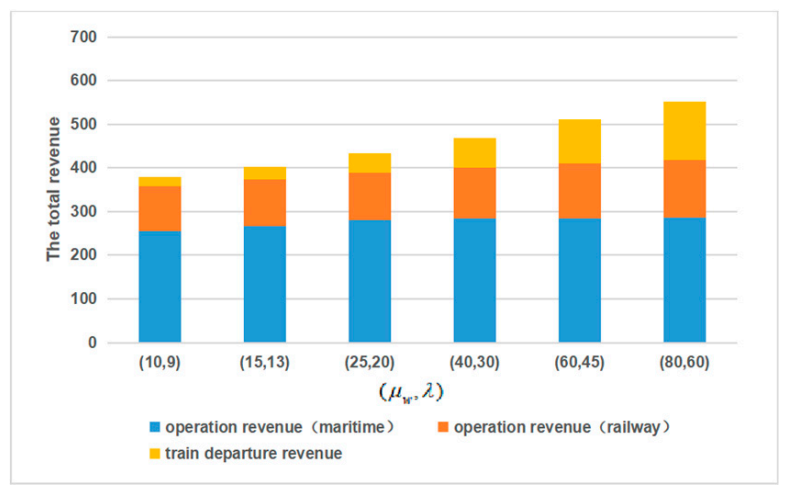

(b)

Figure 5. The composition of the total revenue in the fixed-length container accumulation mode with cooperation (a) and without cooperation (b).

First, the operation revenues of the maritime and railway terminals are compared. In the fixed-length container accumulation mode, the operation revenues of the maritime and railway terminals in the situations with cooperation are almost as same as the ones in the situations without cooperation under all demand. In the fixed-time container accumulation mode, the operation revenues of the maritime and railway terminals in the situations with cooperation are worse than the corresponding ones in the situations without cooperation under all demand. However, its differences between the situations with and without cooperation become smaller with the increase of the intermodal transportation demands. These can be explained by the steady-state probabilities of the states, as shown in Table 3 . 
The following phenomena are observed both under the small and large demand. In the fixed-length container accumulation mode, the steady state probabilities are almost the same between the situations with and without cooperation. Whereas, in the fixed-time container accumulation mode, the higher probabilities are distributed in the states with larger number of containers in the terminals (i.e., larger $(x, y))$ in the situations without cooperation, compared with the situations with cooperation.

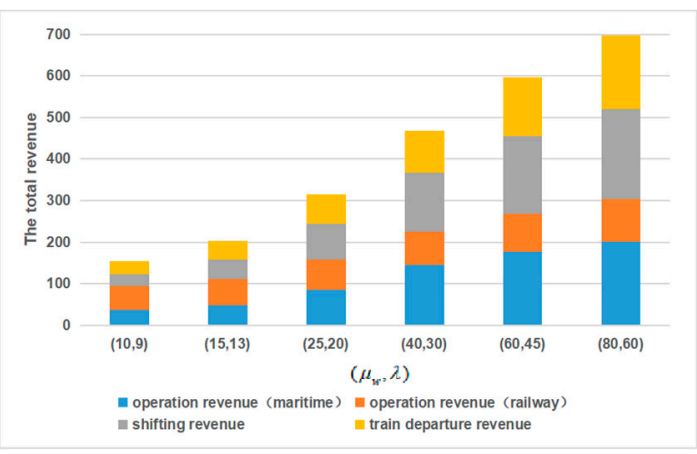

(a)

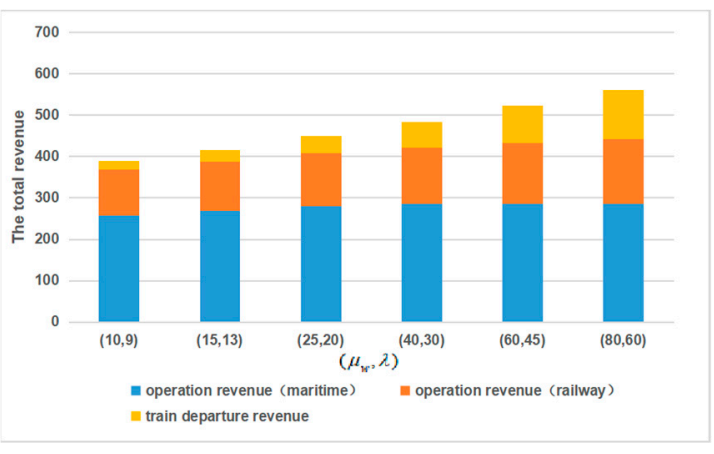

(b)

Figure 6. The composition of the total revenue in the fixed-time container accumulation mode with cooperation (a) and without cooperation (b).

Then, the train departure revenues and the shifting revenues are compared. For both container accumulation modes, these revenues in the situations with cooperation are better than the ones in the situations without cooperation under all demands, as shown in Figures 5 and 6 . This is because the information of the number of containers accumulated in the railway terminal is shared in the situations with cooperation. In the accelerated accumulation scenarios, the containers are induced to shift from truck to train, and the number of departure trains also increase. When the intermodal transport demand becomes larger, the accumulation of containers in the railway terminal accelerates dramatically.

Table 3. The steady-state probabilities of the states.

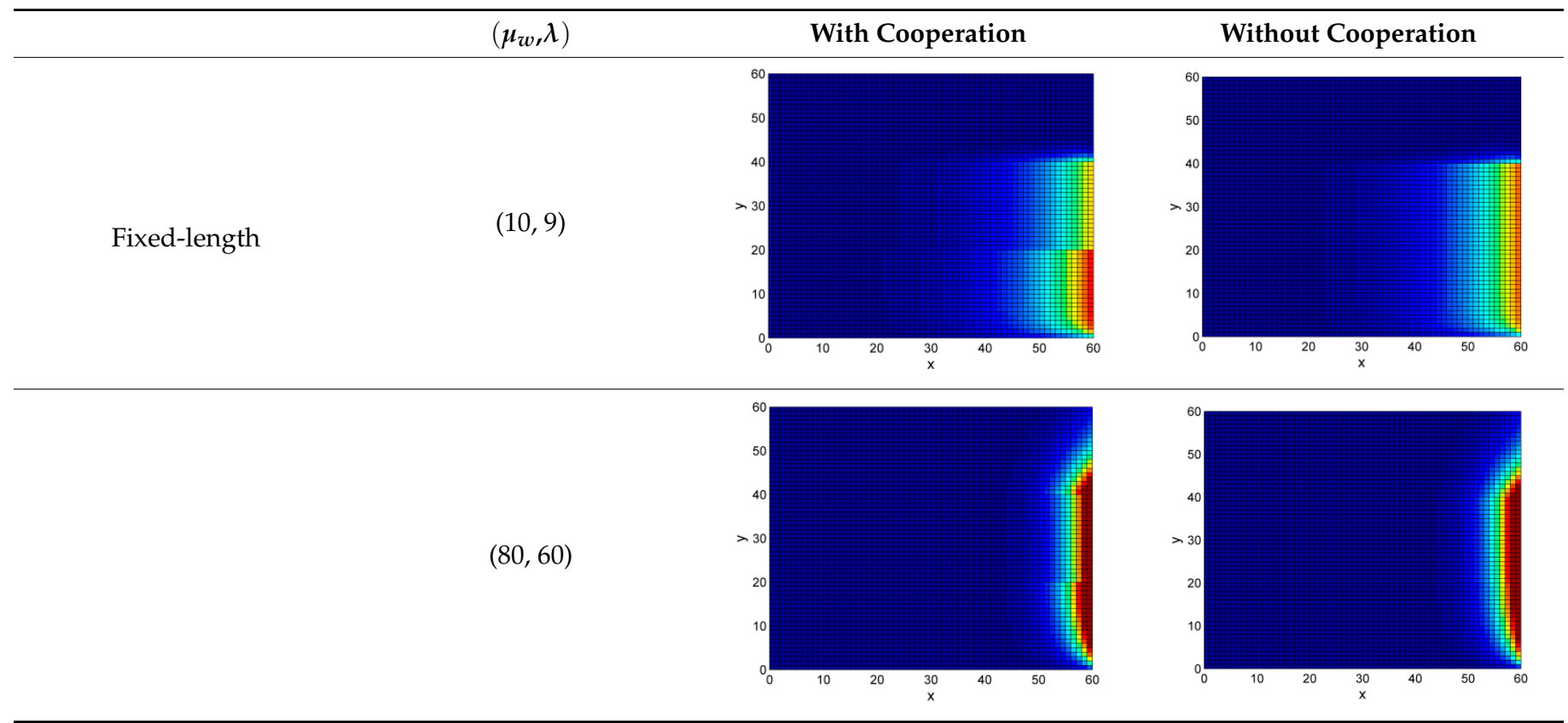


Table 3. Cont.
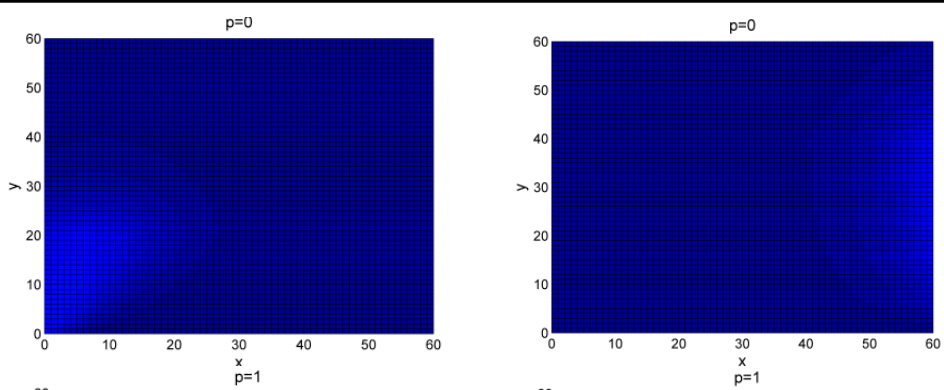

Fixed-time
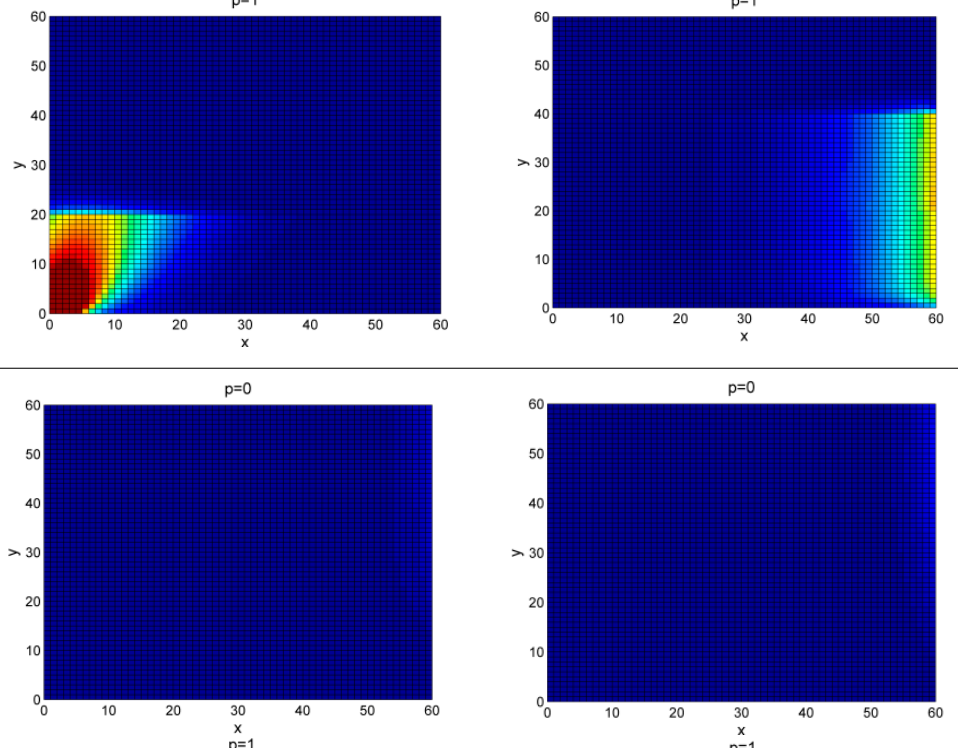

$(80,60)$
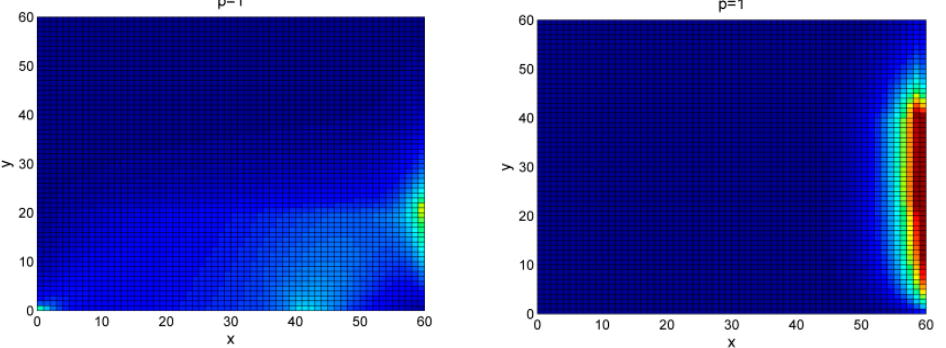

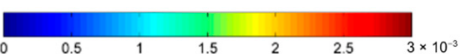

Overall, the situations with cooperation perform better than the situation without cooperation under all demands in the fixed-length container accumulation mode, and under large demands in the fixed-time container accumulation mode, respectively.

Furthermore, the comparisons of the total revenues between the two container accumulation modes in the situations with cooperation can explain the results of Section 4.2. As shown in Figures $5 \mathrm{a}$ and $6 \mathrm{a}$, the operation revenues of the maritime and railway terminals in the fixed-time container accumulation mode are less than the fixed-length container accumulation mode. However, their differences decrease gradually, as the intermodal transportation demands increase. This can be explained by the steady-state probabilities of states, as shown in Table 3 in the situations with cooperation. Comparing with the fixed-time container accumulation mode, the higher probabilities are distributed at the states with larger number of containers in the maritime and railway terminals (i.e., larger $(x, y))$ in the fixed-length container accumulation mode, under both small and large intermodal transportation demand. In the fixed-time container accumulation mode, the higher probabilities move from the states with small number of the containers to the states with large number of the containers in the terminals (i.e., from small $(x, y)$ to large $(x, y))$, as 
the demand increases. On the other hand, as shown in Figures $5 \mathrm{a}$ and $6 \mathrm{a}$, the shifting revenues and the train departure revenues of the fixed-time container accumulation mode increase much faster than the fixed-length container accumulation mode, as the demands increase. Hence, the fixed-time container accumulation mode with large ratios of $\theta_{1}$ to $\theta_{2}$ (i.e., $(0.5,0.1))$ is worse under the small intermodal transportation demand and is better under the large intermodal transportation demand, compared with the fixed-length container accumulation mode.

\subsection{Effects of the Rate $\alpha$}

The impact of parameter $\alpha$ on the total revenue is studied in this section. $\alpha$ represents the railway transportation preference rates, which are set to $0.1,0.2, \ldots$, and 1.0. For example, $\alpha=1$ means all containers are transported by railway to the CR Express consolidation hub and no containers are transported by truck. In this section, the following parameters are fixed for simplicity: $\left(\mu_{w}, \lambda\right)$ is set at $(15,13)$, and $\left(\theta_{1}, \theta_{2}\right)$ is set at $(0.5,0.1)$ as an example to present the fixed-time container accumulation mode.

Figure 7 shows the effect of $\alpha$ on the total revenues of the fixed-length container accumulation mode. With the increase of $\alpha$, the operation revenues of the maritime are almost the same, and the operation revenues of the railway terminal increase. These can be explained by Figure 8 . Figure 8 shows that the higher probabilities are distributed to the states of the larger number of the containers in the railway terminal (i.e., larger $y$ ), as $\alpha$ increases. However, the higher probabilities are distributed to the states of large number of containers in the maritime terminal (i.e., almost similar ranges of $x$ ) for all $\alpha$. The shifting revenue increases first and then decreases as the value of $\alpha$ increases. When $\alpha=1$, there is no shifting revenue. Because there is no container previously planned to transport by truck, no container needs to shift from truck to train. The train departure revenue consistently increases as $\alpha$ increases. Overall, the total revenues increase as the value of $\alpha$ increases. Therefore, it is suggested to increase the willingness of consigners to choose the railway mode to increase the total revenue. It is noted that the degree of increase becomes much smaller when $\alpha$ reaches 0.6 .

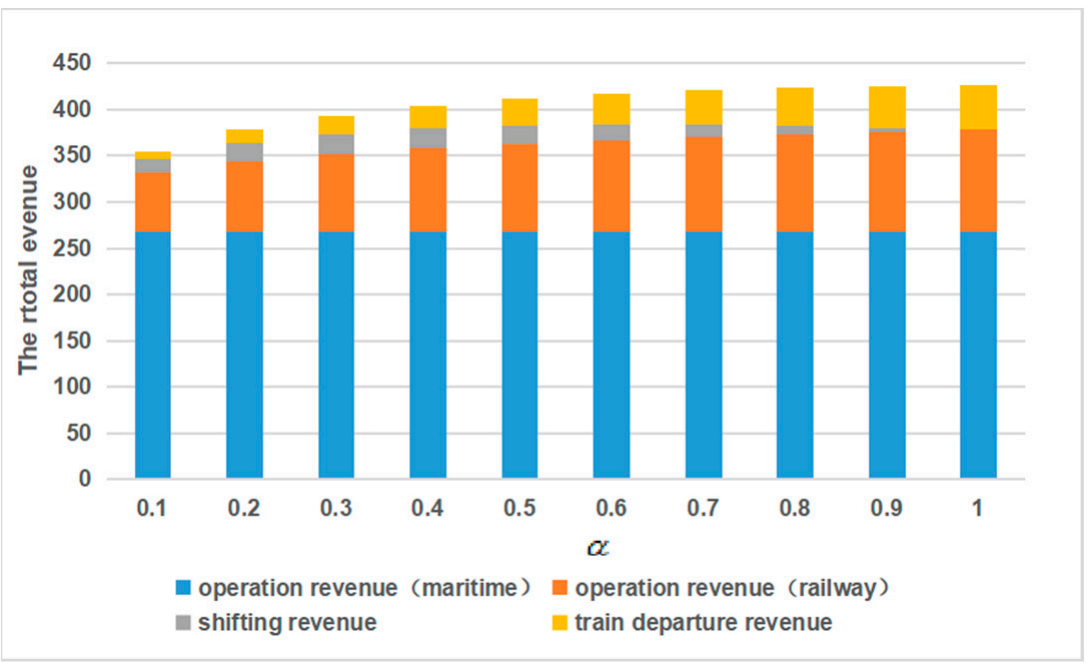

Figure 7. The effect of $\alpha$ on the total revenue in the fixed-length container accumulation mode. 


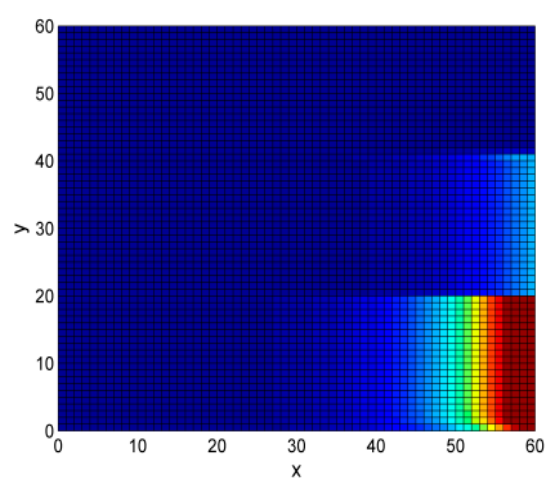

(a)

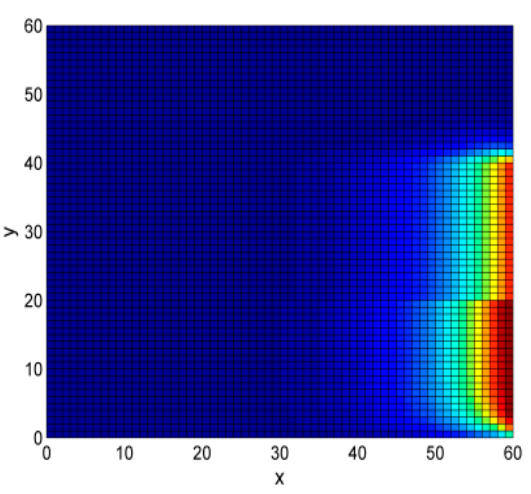

(b)

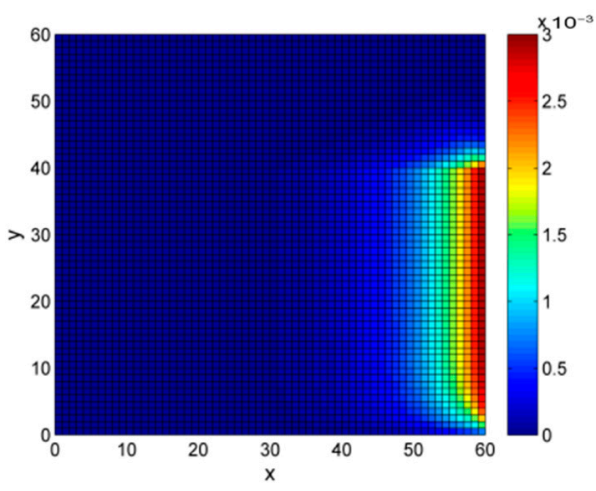

(c)

Figure 8. The steady-state probability of the state in the fixed-length container accumulation mode under demand $(15,13)$ for $\alpha=0.1(\mathbf{a}), \alpha=0.6(\mathbf{b})$, and $\alpha=1$ (c).

Figure 9 shows the effect of $\alpha$ on the total revenues of the fixed-time container accumulation mode. The operation revenues of the maritime terminal decrease significantly, and the operation revenues of the railway terminal increase slightly as $\alpha$ increases. Figure 10 shows the distribution of the higher probabilities moving to the states of the smaller number of the containers in the maritime terminal (i.e., smaller $x$ ), as $\alpha$ increases. The distribution of the higher probabilities remains in the states of small number of containers in the railway terminal (i.e., almost the same range as $y$ ), for all $\alpha$. The shifting revenues and the train departure revenues increase as the value of $\alpha$ increases. In summary, first, the total revenues significantly decrease, and then increase as the value of $\alpha$ increases. The largest total revenue is reached at $\alpha=0.1$, where the operation revenues of the maritime terminal account for the majority of the total revenue, as Figure 9 illustrates. It is the mutually beneficial and sustainable way for the cooperation between the maritime and the railway terminals. Although the maximum total revenue is not obtained, it is better to set $\alpha$ more than 0.5 .

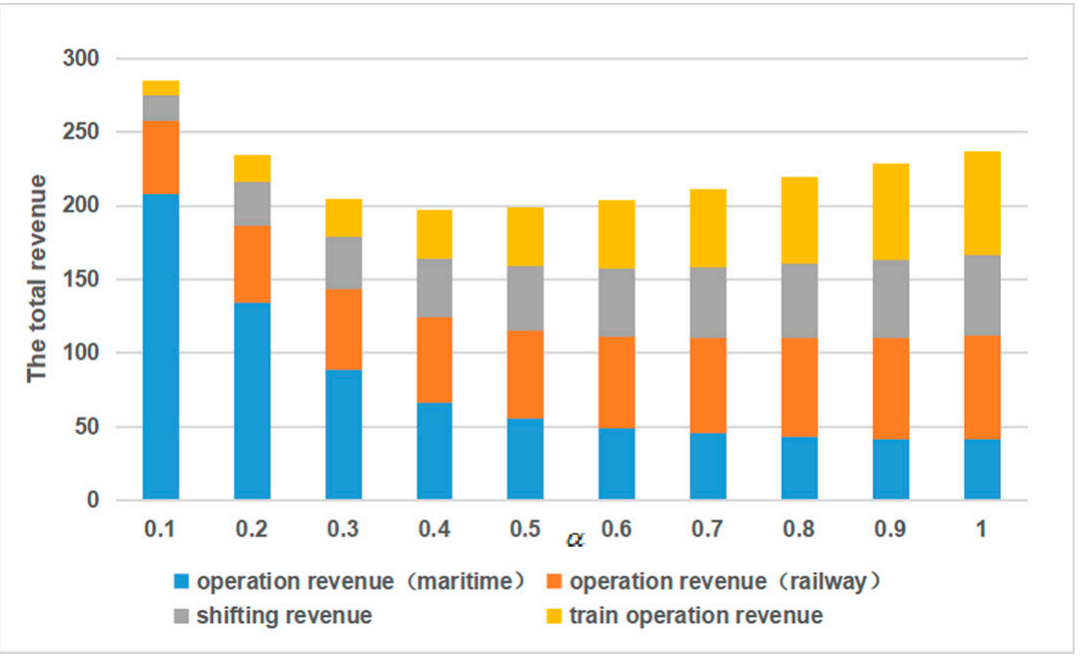

Figure 9. The effect of $\alpha$ on the total revenue in the fixed-time container accumulation mode. 


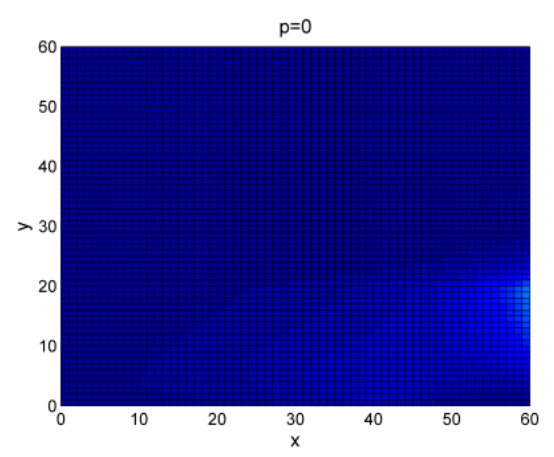

$p=1$

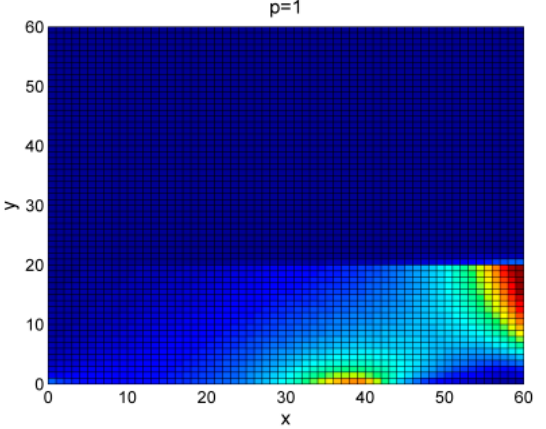

(a)

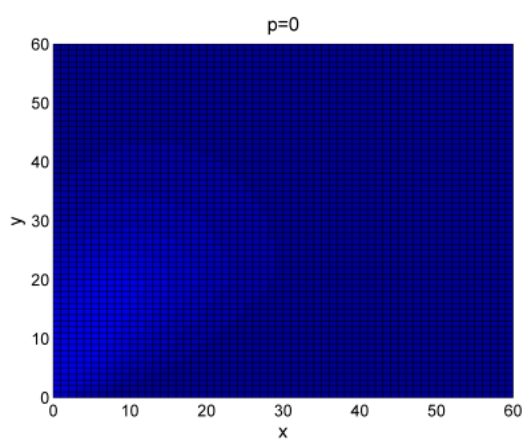

$p=1$

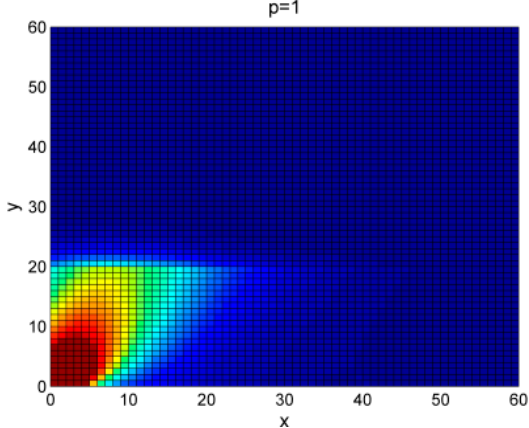

(b)

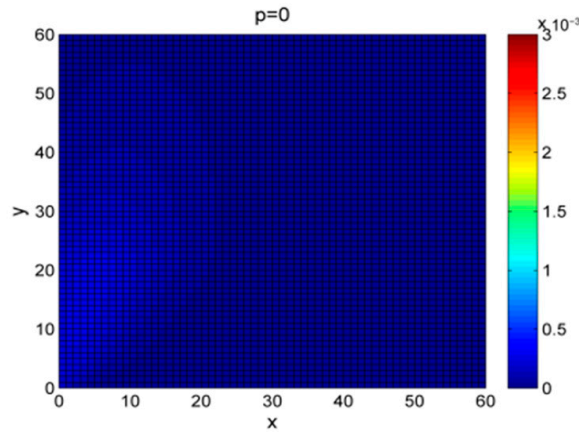

$p=1$

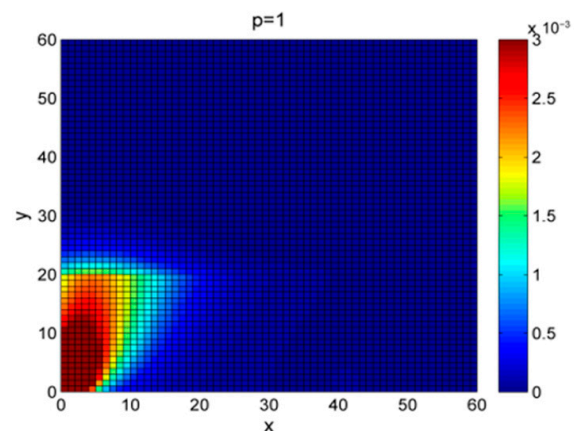

(c)

Figure 10. The steady-state probability of the state in the fixed-time container accumulation mode under demand $(15,13)$ for $\alpha=0.1(\mathbf{a}), \alpha=0.6(\mathbf{b})$, and $\alpha=1$ (c).

\section{Conclusions}

The intermodal container terminal system that connects the maritime route and the CR Express route is investigated in this study. The containers are stored in the maritime terminal and the railway terminal and then are transported to the consolidation hub of $\mathrm{CR}$ Express by truck or train. The intermodal container terminal system can be formulated as the two-echelon dual-channel model. In this study, two-echelon dual-channel models of the fixed-length and the fixed-time container accumulation modes are proposed. The total revenue that consists of the operation revenue, the shifting revenue, and the train departure revenue is used as the key system performance indicator. Numerical experiments indicate that the fixed-length and the fixed-time container accumulation modes should be carefully selected according to the intermodal transportation demand. Additionally, the working and vacation duration (represented by $\theta_{1}$ and $\theta_{2}$ ) should be well designed in the fixed-time container accumulation mode. The results further manifest that the maritime terminal and the railway terminal need not cooperate when the intermodal transportation demand is small, whereas the two terminals should cooperate as the intermodal transportation demands increase.

For the future research, our proposed models can be further extended. In this paper, it is assumed that the containers in the system have the same destination, and only one train leaves the railway terminal at a time. These assumptions can be removed. Moreover, the proposed method in this study can be applied not only in the intermodal container terminals of the CR Express, but also in the other intermodal container terminals.

Author Contributions: Conceptualization, S.G. and K.T.; methodology, S.G. and C.D.; software, C.D.; formal analysis, G.L. and C.D.; investigation, C.D.; writing-original draft preparation, S.G., G.L. and C.D.; writing-review and editing, S.G., C.D., K.T. and G.L.; supervision, G.L. All authors have read and agreed to the published version of the manuscript.

Funding: This study was funded by the National Natural Science Foundation of China, grant number 71302085; China Postdoctoral Science Foundation, grant number 2018M631781; Belt \& Road Program of China Association for Science and Technology, grant number 2020ZZGJB072032; Joint Program 
of Liaoning Provincial Natural Science Foundation of China, grant number 2020HYLH49; Leading Talents Support Program of Dalian Municipal Government, grant number 2018-573; Fundamental Research Funds for the Central Universities, grant numbers 3132020160 and 3132019301.

Institutional Review Board Statement: Not applicable.

Informed Consent Statement: Not applicable.

Data Availability Statement: Not applicable.

Acknowledgments: The authors would like to thank the anonymous reviewers who provided many helpful suggestions for improvements.

Conflicts of Interest: The authors declare no conflict of interest.

\section{Appendix A}

Matrices $G^{1}, G^{2}, L, H^{1}, H^{2}, K, M^{1}$, and $M^{2}$ in $Q^{1}$ are defined as follows:

$$
\begin{aligned}
& G^{1}=\begin{array}{cc}
(k, y, 0) & (k, y, 1) \\
(k, y, 0) & {\left[\begin{array}{ll} 
& \theta_{1} \\
\theta_{2} &
\end{array}\right]}
\end{array} \\
& G^{2}=\begin{array}{ccc}
(k, y, 0) & (k, y, 0) & (k, y, 1) \\
(k, y, 1) & {\left[\begin{array}{cc} 
& \theta_{1} \\
\theta_{2} & -\mu_{l}
\end{array}\right]}
\end{array} \\
& L=\left[\begin{array}{ll}
0 & 0 \\
0 & 1
\end{array}\right]
\end{aligned}
$$

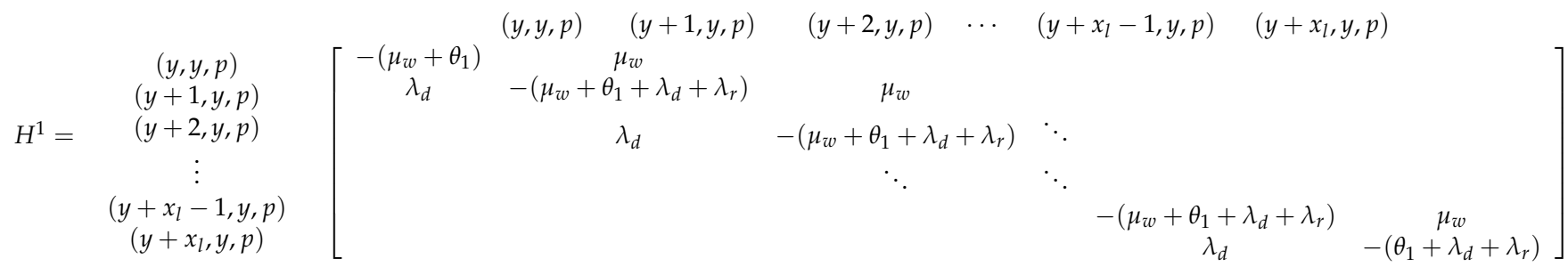

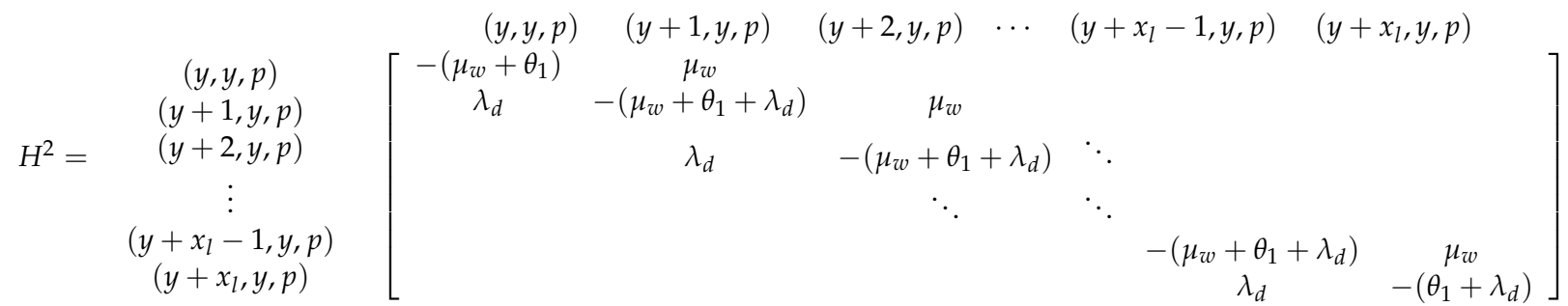

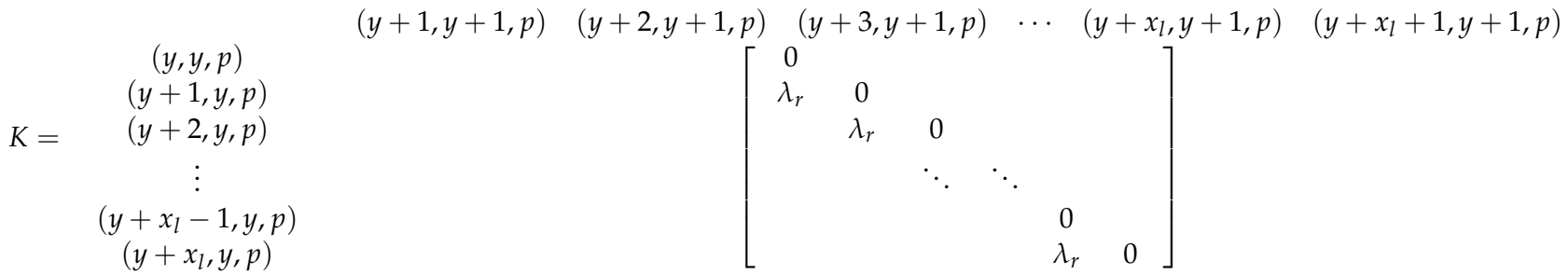




$$
\begin{aligned}
& (0,0, p) \quad(1,0, p) \quad(2,0, p) \quad \cdots \quad\left(y+x_{l}-b, 0, p\right) \\
& \begin{array}{c}
(y, y, p) \\
(y+1, y, p)
\end{array} \\
& M^{1}=(b-y, y, p) \\
& (b-y+1, y, p) \\
& (b-y+2, y, p) \\
& \left(y+x_{l}, y, p\right)
\end{aligned}
$$

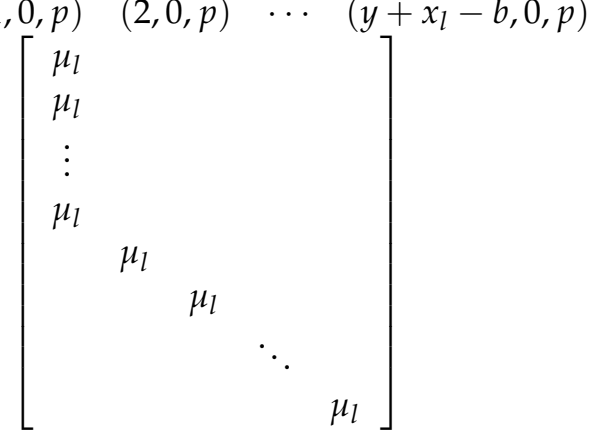

$$
\begin{aligned}
& (y-b, y-b, p) \quad(y-b+1, y-b, p) \\
& M^{2}=\begin{array}{c}
(y, y, p) \\
(y+1, y, p) \\
(y+2, y, p) \\
\vdots \\
\left(y+x_{l}, y, p\right)
\end{array} \\
& {\left[\begin{array}{ll}
\mu_{l} & \\
& \mu
\end{array}\right.} \\
& (y-b+2, y-b, p) \quad \cdots \quad\left(y-b+x_{l}, y-b, p\right) \\
& \mu_{l} \\
& \mu_{l}
\end{aligned}
$$

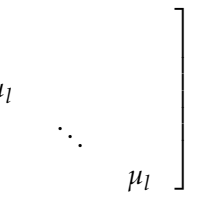

\section{References}

1. Zhao, L.; Zhao, Y.; Hu, Q.; Li, H.; Stoeter, J. Evaluation of consolidation center cargo capacity and loctions for China railway express. Transp. Res. Part E Logist. Transp. Rev. 2018, 117, 58-81. [CrossRef]

2. Wang, Y.; Yeo, G.T. Intermodal route selection for cargo transportation from Korea to Central Asia by adopting Fuzzy Delphi and Fuzzy ELECTRE I methods AU-Wang, Ying. Marit. Policy Manag. 2018, 45, 3-18. [CrossRef]

3. Takahashi, K.; Aoi, T.; Hirotani, D.; Morikawa, K. Inventory control in a two-echelon dual-channel supply chain with setup of production and delivery. Int. J. Prod. Econ. 2011, 133, 403-415. [CrossRef]

4. Cordeau, J.F.; Toth, P.; Vigo, D. A Survey of Optimization Models for Train Routing and Scheduling. Transp. Sci. 1998, 32, 380-404. [CrossRef]

5. Du, Q.; Shi, X.; Bai, L.; Gao, S. Performance analysis of container yard based on batch service queueing system. J. Interdiscip. Math. 2018, 21, 747-760. [CrossRef]

6. Yan, B.; Jin, J.G.; Zhu, X.; Lee, D.H.; Wang, L.; Wang, H. Integrated planning of train schedule template and container transshipment operation in seaport railway terminals. Transp. Res. Part E Logist. Transp. Rev. 2020, 142, 102061. [CrossRef]

7. Di Febbraro, A.; Sacco, N.; Saeednia, M. An agent-based framework for cooperative planning of intermodal freight transport chains. Transp. Res. Part C Emerg. Technol. 2016, 64, 72-85. [CrossRef]

8. Jiang, Y.; Sheu, J.B.; Peng, Z.; Yu, B. Hinterland patterns of China Railway (CR) express in China under the Belt and Road Initiative: A preliminary analysis. Transp. Res. Part E Logist. Transp. Rev. 2018, 119, 189-201. [CrossRef]

9. Shao, Z.Z.; Ma, Z.J.; Sheu, J.B.; Gao, H.O. Evaluation of large-scale transnational high-speed railway construction priority in the belt and road region. Transp. Res. Part E Logist. Transp. Rev. 2018, 117, 40-57. [CrossRef]

10. Sun, W.J.; Zhao, L.J.; Wang, C.C.; Li, D.Q.; Xue, J. Selection of consolidation centres for China Railway Express. Int. J. Logist. Res. Appl. 2020, 23, 417-442. [CrossRef]

11. Wang, X.; Wong, Y.D.; Li, K.X.; Yuen, K.F. Transport research under Belt and Road Initiative: Current trends and future research agenda. Transp. A Transp. Sci. 2020, 8, 1-23.

12. Jung, J.Y.; Wang, W.; Cho, S.W. The Role of Confucius Institutes and One Belt, One Road Initiatives on the Values of Cross-Border M\&A: Empirical Evidence from China. Sustainability 2020, 12, 10277.

13. Yii, K.J.; Bee, K.Y.; Cheam, W.Y.; Chong, Y.L.; Lee, C.M. Is Transportation Infrastructure Important to the One Belt One Road (OBOR) Initiative? Empirical Evidence from the Selected Asian Countries. Sustainability 2018, 10, 4143. [CrossRef]

14. Menhas, R.; Mahmood, S.; Tanchangya, P.; Safdar, M.N.; Hussain, S. Sustainable Development under Belt and Road Initiative: A Case Study of China-Pakistan Economic Corridor's Socio-Economic Impact on Pakistan. Sustainability 2019, 11, 6143. [CrossRef]

15. Yang, D.; Pan, K.; Wang, S. On service network improvement for shipping lines under the one belt one road initiative of China. Transp. Res. Part E Logist. Transp. Rev. 2018, 117, 82-95. [CrossRef]

16. Kuzmicz, K.A.; Pesch, E. Approaches to empty container repositioning problems in the context of Eurasian intermodal transportation. Omega 2019, 85, 194-213. [CrossRef]

17. Xie, Y.; Liang, X.; Ma, L.; Yan, H. Empty container management and coordination in intermodal transport. Eur. J. Oper. Res. 2017, 257, 223-232. [CrossRef]

18. Wei, H.; Dong, M. Import-export freight organization and optimization in the dry-port-based cross-border logistics network under the Belt and Road Initiative. Comput. Ind. Eng. 2019, 130, 472-484. [CrossRef] 
19. Shi, X.; Vanelslander, T. Design and evaluation of transportation networks: Constructing transportation networks from perspectives of service integration, infrastructure investment and information system implementation. Netnomics Econ. Res. Electron. Netw. 2010, 11, 1-4. [CrossRef]

20. Carlo, H.J.; Vis, I.F.A.; Roodbergen, K.J. Storage yard operations in container terminals: Literature overview, trends, and research directions. Eur. J. Oper. Res. 2014, 235, 412-430. [CrossRef]

21. Guo, X.; Huang, S.; Hsu, W.; Low, M. Yard crane dispatching based on real-time data driven simulation for container terminals. In Proceedings of the 2008 Winter Simulation Conference, Miami, FL, USA, 7-10 December 2008; pp. $2648-2655$.

22. Shi, X.; Tao, D.; Voß, S. RFID Technology and its Application to Port-Based Container Logistics. J. Organ. Comput. Electron. Commer. 2011, 21, 332-347. [CrossRef]

23. Hu, L.; Shi, X.; Voß, S.; Zhang, W. Application of RFID Technology at the Entrance Gate of Container Terminals. In Proceedings of the International Conference on Computational Logistics (ICCL 2011), Hamburg, Germany, 19-22 September 2011; pp. 209-220.

24. Boysen, N.; Fliedner, M.; Jaehn, F.; Pesch, E. A Survey on Container Processing in Railway Yards. Transp. Sci. 2013, 47, 312-329. [CrossRef]

25. Hu, Q.; Corman, F.; Wiegmans, B.; Lodewijks, G. A tabu search algorithm to solve the integrated planning of container on an inter-terminal network connected with a hinterland rail network. Transp. Res. Part C Emerg. Technol. 2018, 91, 15-36. [CrossRef]

26. Caballini, C.; Pasquale, C.; Sacone, S.; Siri, S. An Event-Triggered Receding-Horizon Scheme for Planning Rail Operations in Maritime Terminals. IEEE Trans. Intell. Transp. Syst. 2014, 15, 365-375. [CrossRef]

27. Diao, C.J.; Guo, S.J.; Li, G.; Wang, X.H.; Jin, Z.H. Integrated planning for the intermodal container terminals of the CR Express based on Markov process. In Proceedings of the 10th International Conference on Logistics, Informatics and Service Sciences (LISS 2020), Beijing, China, 26-27 July 2020.

28. Grassmann, W.K.; Stanford, D.A. Matrix Analytic Methods. In Computational Probability, 1st ed.; Springer: Boston, MA, USA, 2000; pp. 153-203. ISBN 978-1-4757-4828-4_6. 